\title{
Aspectos contextuais na construção da cogestão em Unidades Básicas de Saúde
}

\author{
Contextual aspects of co-management implementation in Basic \\ Health Units
}

Giovanna Cabral Doricci', Carla Guanaes-Lorenzi

DOI: $10.1590 / 0103-1104202012708$

RESUMO A Política Nacional de Humanização tem como objetivo promover os princípios doutrinários preconizados pelo Sistema Único de Saúde, sendo a cogestão uma de suas diretrizes. Este artigo tem como objetivo descrever e compreender como aspectos contextuais favorecem ou limitam a construção da cogestão no âmbito da Atenção Básica. Trata-se de um estudo empírico e qualitativo desenvolvido em duas unidades de saúde, sendo uma tradicional e uma com Estratégia Saúde da Família (ESF). A construção do corpus se deu por meio de imersão no campo e de diário para anotação de observações e reflexões, analisados por agrupamento temático. Como resultados, descrevemos os aspectos contextuais da ESF, i.e., horário de funcionamento, equipe multiprofissional e necessidade de reuniões, formação do médico, agentes comunitários, e organização do espaço físico como facilitadores para o funcionamento em cogestão. Já os elementos contextuais da unidade tradicional, foram a estrutura organizacional, modelo médico e ausência de reuniões, horário de funcionamento, e organização do espaço físico como dificultadores para essa construção. Esperamos que esta análise promova iniciativas que considerem a importância dos aspectos estruturais, e não só o protagonismo dos sujeitos, como imprescindíveis para o processo de mudança.

PALAVRAS-CHAVE Gestão em saúde. Humanização da assistência. Administração em saúde.

\begin{abstract}
The National Humanization Policy aims to promote the ideological principles advocated by the Unified Health System. Co-management is one of its guidelines. This article aims to describe and understand how contextual aspects favor or limit co-management within the Primary Care. The study is empirical and qualitative, developed in two health units, one traditional and one with a Family Health Strategy (FHS). The data was collected by immersion in the field and a field notes, to record observations and reflections, which were analyzed by thematic categorization. As results, the contextual aspects of the FHS are described: opening hours, multi-professional team and need for meetings, training of doctors, community agents, and organization of the physical space as facilitators to co-management. The contextual elements of the traditional unit, on the other hand: organizational structure, medical model and absence of meetings, opening hours, physical space, hinder co-management. The analysis could be usefull to promote initiatives that consider the importance of structure, in addition to the protagonism of the subjects, as essential for the process of change.
\end{abstract}

KEYWORDS Health management. Humanization of assistence. Health administration.

1 Universidade de São Paulo (USP) - São Paulo (SP), Brasil.

carlaguanaes@gmail.com 


\section{Introdução}

A Política Nacional de Humanização (PNH), uma das principais políticas de saúde do Brasil por alguns anos, objetiva fortalecer o processo da Reforma Sanitária. Organizada por princípios e diretrizes, sendo a cogestão, objeto de pesquisa do estudo aqui relatado, uma das diretrizes centrais. A escolha da cogestão se deve à lacuna observada quanto a esse tema em revisão de literatura sobre a $\mathrm{PNH}^{1}$.

O termo humanização foi ao longo dos anos sendo apropriado, e, ao mesmo tempo, transformado e reconstruído. Minayo ${ }^{2}$ faz um resgate histórico, e Deslandes ${ }^{3}$, ao recapitular a contribuição da sociologia médica, indica algumas vertentes de análise e aspectos do debate no contexto brasileiro. O que nos chama a atenção é a centralidade que a relação profissional de saúde-paciente ocupa nas análises, sendo posterior, em termos históricos, às discussões sobre processos de trabalho e gestão. Como afirmam Deslandes e Mitre 4 , há certa banalização da humanização quando a ela estão associados sentidos de bondade nas relações, nem sempre havendo reflexões a respeito das implicações políticas e práticas de sua promoção. Em consonância, Valadão, Lins e Carvalho ${ }^{5}$ comentam que os profissionais de saúde desconhecem a amplitude da $\mathrm{PNH}$, relacionando-a somente às práticas de acolhimento.

Ao contrário do que esses autores indicam sobre uma significação simplista da humanização, Nora e Junges ${ }^{6}$, com base em revisão sistemática de 40 textos, indicam que essa é considerada pelos profissionais como prática concreta que interfere e modifica o modo de agir e cuidar. Os autores afirmam, ainda, que a política não depende de normas, protocolos ou aparatos burocráticos, mas, primordialmente, do empenho dos diferentes sujeitos envolvidos no processo. Embora não desconsideremos esse apontamento, avaliamos que essa ideia, se tomada de forma absoluta, pode parecer perversa. Entre outros aspectos, pode levar à desconsideração da influência do contexto, o que, neste artigo, significa modelo de atenção, estrutura organizacional, processos de trabalho e estrutura física das unidades de saúde.

Em resumo, argumentamos que, de um lado, a PNH agrupa princípios e fundamentos doutrinários que objetivam favorecer a democracia, valorizando as relações e subjetividades. Por outro lado, essa valorização do protagonismo pode tornar o Estado omisso em suas responsabilidades, permanecendo a impressão de que as mudanças dependem, quase que exclusivamente, das pessoas e de suas relações no cotidiano. A partir de uma análise marxista, Souza e Maurício ${ }^{7}$ comentam não se tratar somente de uma valorização do envolvimento emocional e comunicacional, mas também de incluir a produção das condições sociais, que são desumanizadoras em nossas análises.

Esses aspectos revelam a complexidade da PNH e as implicações de seus fundamentos, os quais vêm sendo compreendidos a partir de diferentes lentes teóricas e metodológicas ${ }^{\mathbf{3}, 8}$. A partir de referencial epistemológico construcionista social, consideramos relevante abarcar o contexto social, histórico e cultural, além do contexto local, em que as relações se constroem. Compreendemos e defendemos as mudanças a partir das tecnologias leves, mas, ao mesmo tempo, levantamos duas questões centrais que guiaram nossa pesquisa: Quais aspectos contextuais circunscrevem as relações? Como tais aspectos limitam ou potencializam a concretização das transformações almejadas e descritas como princípios e diretrizes da $\mathrm{PNH}$ especificamente em relação à cogestão na cartilha do Ministério da Saúde (MS) referente a esse tema ${ }^{9}$ ?

Em revisão sistemática sobre a $\mathrm{PNH}$ na Atenção Básica (AB), Nora e Junges ${ }^{6}$ concluem $^{2}$ que a maioria dos estudos analisados relatam pesquisas realizadas com profissionais de saúde e usuários. Somente quatro dos estudos foram feitos com profissionais, usuários e gestores; $\mathrm{e}$ apenas um com profissionais e gestores.

Com relação à metodologia, a maioria dos estudos utilizou entrevistas, e, em menor quantidade, observação participante ${ }^{6}$. Embora seja objeto de pesquisas desde a sua criação, 
a humanização permanece ainda pouco explorada no cotidiano das práticas de gestão, especialmente no contexto da AB. Da mesma forma, os estudos têm priorizado como metodologia as entrevistas ou conversas com profissionais e usuários, sendo poucos os que relatam a prática a partir de observação.

Com base na literatura estudada e na existência de poucos estudos sobre a PNH com foco na gestão e no contexto da $\mathrm{AB}$, delineamos como objetivo central deste artigo descrever e compreender, a partir de pesquisa empíri$\mathrm{ca}$, aspectos contextuais que favorecem ou limitam a construção de uma gestão tal como preconiza a PNH. Diferentemente da maioria dos estudos descritos na revisão realizada por Nora e Junges ${ }^{6}$, utilizamos recursos da pesquisa qualitativa tais como imersão no campo e anotações em diário de campo, os quais nos permitiram maior apropriação do contexto local e das práticas em cada unidade.

Definimos o termo gestão incluindo as relações estabelecidas no cotidiano das práticas e o modo como se organiza o trabalho, considerando a estrutura dos contextos locais e usuários, algo também bastante valorizado pela PNH. Para delineamento da pesquisa, análise e discussão em relação aos aspectos contextuais que limitam ou potencializam a cogestão, utilizamos os norteadores centrais que definem a cogestão, descrita a seguir.

\section{Cogestão na PNH}

A partir da compreensão de que atenção e gestão são indissociáveis, a PNH, por ser uma política transversal, prevê alterações tanto nos modos de cuidar como nos modos de gerir. Nesse sentido, apresenta diferentes frentes de ação, que, embora sejam teoricamente bastante específicas, na prática, interferem umas nas outras e em todo sistema organizativo. Dentre as diretrizes da PNH está a cogestão, a qual indica um modelo de gestão que objetiva fomentar, no âmbito da gestão, os princípios norteadores da política.
A cogestão fundamenta-se, em grande parte, na obra de Campos ${ }^{10}$, que, ao assumir o cargo de secretário executivo da Secretaria Executiva do Ministério da Saúde em 2003, passou a produzir conhecimento e a influenciar os textos de algumas políticas nacionais ${ }^{\mathbf{1 1}}$. Compreendemos que a $\mathrm{PNH}$ englobe outras produções e autores, porém, no âmbito da gestão essa obra se destaca ${ }^{8}$.

O objetivo central de Campos $^{10}$ foi criar um método que possibilitasse analisar e cogerir coletivos, algo que o autor construiu por meio da reformulação de conceitos do campo da administração e de outras áreas como política, psicologia, filosofia e pedagogia. Sua obra possui um caráter transdisciplinar e indica que para se realizar a cogestão é necessária a criação de espaços coletivos que cumpram três funções centrais: 1) administração e planejamento; 2) função política - democracia; e 3) função pedagógica e terapêutica, uma vez que influencia a produção de subjetividades, o que ele chama de Fator Paideia.

Campos ${ }^{10}$ defende uma atuação ampliada, que se inicie no interior das unidades de saúde. O Método, diferentemente das teorias de administração e de planejamento que operam no plano do instituído, não se limita à criação de espaços de participação, como se a mera colocação de pessoas em roda fosse capaz de promover as transformações almejadas. É necessário um trabalho que inclua as subjetividades e as relações, de forma que o resultado não seja uma reprodução do instituído nem uma satisfação exclusiva dos desejos individuais, mas um projeto, produto intermediário, que tenha sido construído coletivamente, uma prática social com função administrativa, mas também política, pedagógica e terapêutica.

A partir desse referencial sobre a gestão de coletivos, o MS desenvolveu uma cartilha que descreve a diretriz cogestão da PNH, um modelo centrado no trabalho em equipe, como descrito:

O modelo de gestão que a Política Nacional de Humanização propõe é centrado no trabalho em equipe, na construção coletiva (planeja quem 
executa) e em espaços coletivos que garantem que o poder seja de fato compartilhado, por meio de análises, decisões e avaliações construídas coletivamente ${ }^{\mathbf{9 ( 1 2 )}}$

Há na cartilha a indicação de alguns arranjos e dispositivos que têm como objetivo propiciar as condições mínimas necessárias para a cogestão. Em relação aos arranjos para discussões entre profissionais, usuários e gestores, descreve Grupos de Trabalho de Humanização; Colegiados Gestores de Hospital, de Distritos Sanitários e Secretarias de Saúde; Colegiado Gestor da Unidade de Saúde; Mesa de Negociação Permanente; Contratos de Gestão; Contratos Internos de Gestão; Câmara Técnica de Humanização ${ }^{9}$.

Para que esse modelo de gestão funcione, é necessário que haja condições institucionais e políticas efetivas; uma nova arquitetura que possibilite a comunicação entre os diferentes; e que os profissionais de distintas áreas do conhecimento possam estar em um mesmo espaço e com objetivo comum que transcendam suas especialidades. Como indica a cartilha, a cogestão corre o risco de se tornar mera retórica ${ }^{9}$ sem essas condições concretas.

\section{Material e métodos}

Esta pesquisa possui delineamento qualitativo com fundamentação epistemológica construcionista social, cujo objetivo é compreender as relações estabelecidas entre os sujeitos e os modos como se organizam a partir de determinado contexto social local, histórico e cultural. Como aspecto central, reconhecemos nossa participação ativa e não neutra como pesquisadoras ao longo de todo processo de pesquisa $^{\mathbf{1 2 , 1 3}}$.

Além disso, não há um método específico a ser utilizado, uma vez que todos são considerados opções discursivas que circunscrevem a construção do corpus e os potenciais resultados ${ }^{\mathbf{1 2 , 1 3}}$. Minayo ${ }^{\mathbf{1 4}}$ teoriza, com base na literatura e em sua experiência, um caminho metodológico que serviu como inspiração para a construção e análise do corpus, conforme será descrito.

\section{Aspectos éticos}

O estudo segue a Resolução $\mathrm{n}^{0} 466^{15}$ e foi aprovado pelo Comitê de Ética (CAAE: 46453315.0.0000.5407). Embora, para a imersão no contexto, a autorização dos gerentes das unidades de saúde tenha sido considerada suficiente, iniciamos nosso contato apresentando a pesquisa para as equipes e solicitando suas autorizações.

\section{Contexto e participantes}

O contexto de pesquisa corresponde a duas unidades de saúde do Distrito Oeste de Ribeirão Preto (SP). Escolhemos como campo uma unidade tradicional, sem Programa de Agentes Comunitários de Saúde (Pacs) ou Estratégia Saúde da Família (ESF), e uma com ESF. Foram escolhidas porque contemplam dois modelos de atenção presentes no município e pela facilidade de acesso das pesquisadoras a esses contextos, já que a Universidade e as unidades onde foi desenvolvida a pesquisa estão localizadas no mesmo Distrito de Saúde.

A Unidade Básica de Saúde (UBS) tradicional funciona de segunda à sexta-feira, das 7 h00 às 17h00, e não fecha para almoço. Oferece serviços nas áreas de clínica médica, pediatria, ginecologia e obstetrícia, odontologia, enfermagem, assistência farmacêutica, vacinação e teste do pezinho ${ }^{16}$. A equipe é composta por três médicas clínicas, para as quais adotamos o pronome feminino para evitar identificação, uma vez que a maioria das profissionais são mulheres; duas pediatras e duas G.O.; três enfermeiras, sendo uma delas a gerente da unidade; treze auxiliares de enfermagem; três dentistas; duas auxiliares odontológicas; duas recepcionistas, ou auxiliares administrativas; três farmacêuticas; duas auxiliares de limpeza; e três menores aprendizes. A equipe possui, em média, 35 profissionais fixos e jovens aprendizes. 
O Núcleo de Saúde da Família (NSF) funciona de segunda à sexta-feira das $8 \mathrm{~h} 00$ às $17 \mathrm{~h}$, e fecha por uma hora para o almoço. Há uma equipe mínima de saúde da família, composta por uma enfermeira, uma médica de família, cinco agentes comunitárias, duas auxiliares de enfermagem, uma recepcionista, uma segurança e uma auxiliar de serviços gerais. Há também residentes de diferentes áreas, sendo quatro da medicina, uma da odontologia, uma da nutrição, uma da fonoaudiologia, uma da farmácia e uma da fisioterapia. A equipe é composta, em média, por doze profissionais fixos da equipe mínima mais os residentes. A unidade oferece ações nas áreas de pediatria, clínica médica, ginecologia e obstetrícia, enfermagem, planejamento familiar, acompanhamento de famílias cadastradas e atividades educativas ${ }^{16}$.

\section{Construção do corpus}

Considerando os objetivos e as questões norteadoras apresentadas na introdução, os procedimentos de construção do corpus foram delineados pela imersão no campo, para observação de campo e não participante ${ }^{\mathbf{1 4}}$, ao longo do primeiro semestre de 2016, com o objetivo de nos familiarizar com a rotina de cada uma das unidades de saúde. A pesquisadora, psicóloga, pós-graduanda e não atuante nos contextos da pesquisa permanecia nas unidades de saúde e conversava informalmente com os profissionais, fazendo anotações no diário sempre que algo se aproximava dos objetivos delineados no estudo.

A imersão teve duração de quatro meses, de fevereiro à primeira semana de junho de 2016, e carga horária semanal de quatro horas em cada unidade de saúde. As observações foram feitas de modo alternado. Intercalamos dias da semana e horários, período da manhã e período da tarde com o objetivo de contemplar a rotina de trabalho das unidades. Apesar desse cuidado, sabemos ser impossível conhecer detalhadamente a organização em tão curto período de tempo.

Delineamos como espaço de imersão todos os locais das unidades de trânsito livre.
Assim, circulávamos em todos os espaços, com exceção das salas onde ocorrem consultas ou procedimentos técnicos. Estivemos presentes, sempre que possível, às reuniões das equipes ou às conversas em dupla ou em grupos 'informais', i.e., nos corredores.

Após levantamento da literatura em relação à $\mathrm{PNH}$ e, mais especificamente, à cogestão, construímos um instrumento com questões para serem observados durante a imersão, conforme indica Minayo ${ }^{\mathbf{1 4}}$. Esse instrumento continha questões sobre os princípios e algumas diretrizes da PNH. Por exemplo, quanto ao princípio protagonismo, foram levantadas questões sobre como se configura o papel do gestor ou quem executa, participa do planejamento. Outro aspecto abarcado nesse instrumento foram alguns dispositivos e arranjos de trabalho citados na cartilha ${ }^{9} \mathrm{e}$ na introdução deste artigo.

Para registro dessa imersão, utilizamos diário de campo para cada unidade, instrumento descritivo e reflexivo sobre elementos do contexto ${ }^{14}$. Os diários estão organizados por dia de observação e compõem um total de 214 páginas digitadas em editor de textos.

\section{Procedimento de análise}

Conforme afirma Minayo ${ }^{\mathbf{1 4}}$, a análise centra-se em compreender o material construído. Baseamo-nos, neste recorte, em leituras horizontais e verticais ${ }^{\mathbf{1 4}}$ dos diários de campo com o objetivo de nomear 'aspectos contextuais' que influenciam a construção do modelo de gestão de cada unidade e categorizá-los tematicamente. Para isso, retomamos o conteúdo dos diários na íntegra e fomos construindo um novo documento em que nomeávamos alguns aspectos do contexto e resumíamos o conteúdo. Por exemplo, o trecho:

Todos estavam ali com um objetivo, aparentemente comum, se sentiam responsáveis pelo que conversavam, pareciam livres para expressar suas opiniões [...]. Mesmo com relação aos comentários que a gerente fazia. (Primeiro Dia, Primeiro Mês - NSF). 
Após leitura e análise, foi descrito no novo arquivo a partir da nomeação do aspecto contextual:

1) Reunião de equipe/enfoque multidisciplinar (aspecto do contexto do Núcleo) - corresponsabilidade e certa horizontalidade na tomada de decisões (funcionamento observado).

$\mathrm{O}$ intuito ao fazer esse novo arquivo foi o de reduzir o conteúdo do diário e, ao mesmo tempo, organizar as informações nomeando elementos específicos de cada contexto, conforme indica Minayo ${ }^{\mathbf{1 4}}$. A análise foi realizada de forma didática, separando os elementos, embora consideremos que são, ao mesmo tempo, causa e efeito do modelo de gestão observado, havendo uma retroalimentação entre a estrutura organizacional e o modo como se constrói o processo de trabalho, as relações e a gestão em cada local.

\section{Resultados e discussão}

\section{Aspectos contextuais das unidades de saúde}

\section{NÚCLEO DE SAÚDE DA FAMÍLIA: ASPECTOS HISTÓRICOS E ESTRUTURAIS}

A história de criação do NSF decorre da construção dos demais NSF. A iniciativa foi realizada a partir de 1999 por professores do Departamento de Medicina Social da Faculdade de Medicina de Ribeirão Preto, Universidade de São Paulo, que identificaram a necessidade de haver um espaço para atuação prática da Residência em Medicina Geral e Comunitária com Ênfase em Família. A instalação dessas unidades, a partir de 2001, contou com apoio da Secretaria de Saúde do Estado e do Município, além do apoio de docentes de outras faculdades, como a Escola de Enfermagem, Psicologia, Odontologia, dentre outras ${ }^{17}$.
Os professores que encabeçaram esse projeto montaram uma banca examinadora única para selecionar os profissionais. Houve, desde o início, valorização da cogestão, visto que as reuniões eram incentivadas a acontecer semanalmente. Outro aspecto relevante corresponde ao critério de seleção dos médicos, que, obrigatoriamente, tinham formação em Medicina de Família ${ }^{17}$.

Atualmente, ainda há uma cultura participativa e noção de corresponsabilidade na equipe. Notamos que o modelo organizacional da unidade com ESF possui aspectos estruturais próprios desse modelo, que facilitam a cogestão.

Como afirmam Calderon e Verdi ${ }^{18}$, é necessário que haja condições objetivas para que a cogestão aconteça, como o estabelecimento de tempo e espaço para a reflexão, os quais podem ser considerados parte da estrutura, nomeada aqui como contextual. Assim, os aspectos destacados foram escolhidos por serem considerados centrais à manutenção da cultura observada, quais sejam: horário de funcionamento, equipe multiprofissional e necessidade de reuniões, formação do médico, agentes comunitários, e organização do espaço físico.

\section{HORÁRIO DE FUNCIONAMENTO}

Observamos que, no contexto do NSF, a equipe possui certa flexibilidade e margem para negociar o fechamento da unidade. Embora o horário e a carga horária sejam previstos e predeterminados pela Política Nacional de Atenção Básica (PNAB) e pela Prefeitura, a equipe fechava nos momentos de reunião geral e no horário de almoço.

As reuniões gerais geram como efeito a noção de pertencimento e participação, além de possibilitar o compartilhamento de informações de maneira democrática. Assim, todos têm acesso às questões e demandas do contexto e podem ser convidados a participar, a depender do modo como a reunião ocorre. Além disso, há a condição básica para que todos participem, que é o fechamento da 
unidade. A equipe coloca um aviso no portão sugerindo que apertem a campainha em casos urgentes. A segurança, única da equipe que não participa das reuniões, é a responsável por abrir o portão, e, se for o caso, chamar alguém da equipe.

Com relação ao período de almoço, o fechamento favorece confraternizações e proporciona, inclusive, momentos para contato interpessoal, algo descrito por Lewin, autor de referência sobre grupos de trabalho, como sendo positivo para a manutenção da integração e criatividade no trabalho ${ }^{19}$. Assim, esse aspecto facilita o potencial de construção da cogestão, pois oferece condições para o fortalecimento e integração da equipe.

A nova $\mathrm{PNAB}^{20}$ recomenda que as unidades de saúde funcionem com carga horária de, pelo menos, 40 horas semanais, e mínimo de cinco dias da semana. A portaria também indica como possibilidade a pactuação de horários alternativos, desde que não deixe de atender às necessidades da comunidade. Contudo, há uma recomendação expressa para que a unidade não feche em horário de almoço, "recomenda-se evitar barreiras de acesso como o fechamento da unidade durante o horário de almoço"20(74).

Essa recomendação considera como objeto de análise o acesso, que parece se resumir à abertura da unidade de saúde. Porém, a partir da análise realizada, indicamos que o fechamento pode, a depender do modo como é utilizado, gerar benefícios para a equipe e, consequentemente, gerar maior compromisso no que se refere ao seu trabalho e ao modo como se organizam, considerando, inclusive, o modo como oferecem o acesso. Por outro lado, muitos usuários trabalham em horário comercial e utilizam o horário de almoço para resolver questões do cotidiano. Com o fechamento da unidade, essa parcela da população pode ser prejudicada em suas necessidades, o que nos mostra a importância de se pactuar aspectos como esse coletivamente, em cogestão com a população da área de abrangência.

\section{EQUIPE MULTIPROFISSIONAL E NECESSIDADE DE REUNIÕES}

No modelo de atenção proposto na ESF, o trabalho é realizado por equipe multiprofissional, que é cobrada e avaliada pelo número de reuniões que faz. O Programa de Avaliação e Monitoramento da Atenção Básica, instrumento de avaliação das UBS ao qual o NSF aderiu, inclui como um de seus indicadores a frequência das reuniões. Essa característica da composição da equipe multiprofissional e da necessidade de reuniões favorece o potencial de construção da cogestão, pois, assim como no caso do item anterior, oferece subsídios para que ela aconteça, algo indicado também na cartilha9 e em estudo sobre a cogestão ${ }^{21}$.

\section{FORMAC̣ÃO DO MÉDICO}

Ainda considerando as características do modelo de atenção, consideramos como ideal que o médico possua formação em Medicina de Família para poder atuar na saúde da família. Nesse modelo, o médico é convidado a compreender que o seu papel se complementa com os demais profissionais da equipe.

No contexto específico do NSF participante, a médica responsável fez residência em Medicina de Família e Comunidade em um dos NSF do distrito, tendo uma formação fortemente voltada para a integralidade e para o fortalecimento do trabalho da equipe multiprofissional. A forma como ela demonstrou compreender a sua atuação e a maneira como ela se posicionava frente à equipe pareceu facilitar o trabalho coletivo em diferentes momentos, o que, conforme análise descrita, favoreceu a construção da cogestão.

\section{AGENTES COMUNITÁRIOS DE SAÚDE}

Como parte importante da equipe multiprofissional desenhada para atuar no modelo da ESF estão os Agentes Comunitários de Saúde. A presença desses profissionais favorece o olhar integral, uma vez que eles são os responsáveis 
por compreender a vida dos usuários para além das demandas apresentadas nas consultas, embora isso nem sempre aconteça ${ }^{5,22}$.

A presença e atuação dos agentes podem funcionar como convite para o cuidado integral. Esse olhar focado na integralidade exige da equipe corresponsabilização, e, portanto, favorece e fomenta a cogestão, mas, obviamente, o simples fato de ter o agente comunitário não garante esses aspectos.

Atualmente, com a nova portaria que regulamenta a PNAB, o papel do agente sofreu algumas alterações. Além de serem incluídas atividades antes atribuídas unicamente aos técnicos de enfermagem, há indicação para que esses profissionais incluam em seu trabalho o papel do agente de endemias ${ }^{20}$. Essas mudanças precisam ser avaliadas com muita cautela, uma vez que o papel do agente comunitário tem sido descrito como fundamental para o bom funcionamento da ESF.

Outro aspecto de mudança a partir da nova $\mathrm{PNAB}$ corresponde à flexibilidade dada aos municípios para compor as equipes, não havendo mais uma indicação do número de agentes $^{\mathbf{2 0}}$. Essas mudanças podem ser vistas como potenciais perdas de algo que ainda estava em plena construção.

\section{ORGANIZAC̣ÃO DO ESPAC̣O FÍSICO}

De acordo com a PNAB,

ambiência de uma UBS refere-se ao espaço físico (arquitetônico), entendido como lugar social, profissional e de relações interpessoais, que deve proporcionar uma atenção acolhedora e humana para as pessoas, além de um ambiente saudável para o trabalho dos profissionais $20(70)$.

Em nossa análise, descrevemos a ambiência do NSF como acolhedora para os usuários, e, do que pudemos observar, funcional para os profissionais. Nossa análise não nos permite dizer se a unidade está equipada com o que se espera em termos de normas, pois não é nosso objetivo descrever esses aspectos, além de não possuirmos competência técnica para tal. Apenas notamos que o espaço onde os usuários aguardam atendimento é arejado, coberto, com bebedouro, bancos e uma pequena brinquedoteca para as crianças. Durante os quatro meses de observação, não presenciamos filas nem pessoas aguardando em pé. Essa organização do espaço nos pareceu garantir conforto mínimo para os usuários, e, também, para os próprios profissionais, que possuem condições físicas e espaciais para realizar as suas atividades, inclusive com relação às reuniões de equipe.

Conforme revisão realizada por Pastana, Pereira, Lima e Schveitzer ${ }^{23}$, a literatura indica como facilitadores das práticas humanizadoras, descritos por profissionais de saúde, dentre outros: a valorização e reconhecimento do trabalho do profissional de saúde, espaço físico adequado, realização de reuniões, equipe bem coordenada e sistema de suporte ao trabalho dos profissionais, o que corrobora nossa análise e resultados apresentados em relação à unidade de saúde participante do estudo.

\section{UNIDADE BÁSICA DE SAÚDE TRADICIONAL: ASPECTOS HISTÓRICOS E ESTRUTURAIS}

A UBS foi inaugurada em 1987, portanto é anterior à Constituição de 1988, que instituiu o SUS. Seu funcionamento inicial mantinha a clínica médica, pediatria, ginecologia e obstetrícia e sala de vacina. Por ser uma unidade antiga, passou por uma série de mudanças ao longo do processo histórico. O modelo de gestão sofreu transformações que acompanhavam os modos de operar dos gerentes nomeados para coordenar a unidade em cada momento. Por um período, tiveram a composição de ESF, em que os médicos já contratados passaram a atuar nesse novo modelo, embora não tivessem formação em Medicina de Família. Posteriormente, a unidade permaneceu somente com o Pacs, que também se extinguiu.

Atualmente, a UBS possui modelo de atenção e estrutura organizacional distintos 
dos que foram descritos sobre o NSF, o que gera um funcionamento da equipe bastante diverso e com pouco subsídio estrutural para a construção da cogestão.

O que se observa nesse contexto é a predominância de uma cultura organizacional fortemente pautada na divisão de tarefas e de responsabilidades por setor, o que implica uma rotina estruturada com baixa necessidade de participação e de compartilhamento das decisões. O critério de escolha dos aspectos destacados abaixo foi, assim como no caso do NSF, observar os efeitos que eles geram, como a possibilidade de manutenção da cultura observada, em que há menor nível de compartilhamento da gestão. São eles a estrutura organizacional, modelo médico e ausência de reuniões, horário de funcionamento, e organização do espaço físico.

\section{ESTRUTURA ORGANIZACIONAL}

A estrutura organizacional da UBS se construiu a partir de um modelo de atenção anterior ao SUS e à ESF. Embora as UBS componham a rede de $A B$ do município e possuam ações próprias e diferentes das do NSF, o modelo de atenção se mantém, em muitos casos, fortemente pautado no modelo médico, e a unidade tende a funcionar como um ambulatório ou pronto-atendimento.

Hoje, as unidades tradicionais podem aderir ao Pacs ou à ESF, desde que respeitados os parâmetros mínimos, mas a estrutura organizacional se mostra bastante diferente de uma unidade de saúde da família, pois não preconiza tão fortemente a atuação da equipe multiprofissional. Assim, consideramos que, mesmo com a implantação do Pacs ou ESF, devido à cultura, algumas dificuldades seriam enfrentadas pelos profissionais para que pudessem atuar como uma equipe corresponsável. No caso da unidade participante do estudo, não há Pacs ou ESF. Houve Pacs no passado, mas os profissionais não viam muito sentido para a atuação dos agentes naquele contexto, uma vez que o enfoque eram, e ainda são, as consultas médicas vistas como independentes.

Pelo que foi possível notar, a unidade participante tem como objetivo oferecer agendamento de consulta em clínica médica, pediatria e ginecologia e obstetrícia. Os profissionais chegam a verbalizar que a unidade tem como foco a prevenção, e descrevem que "ou seja, agendamento de consulta antes que a doença se instale". Interessante notar que esse sentido sobre prevenção de doença e promoção da saúde se constrói de maneira bastante peculiar na interface com o discurso médico, que ignora os determinantes sociais e a definição ampliada de saúde, que não é entendida somente ausência de doença.

Além disso, a unidade oferece serviços como curativos, administração de medicamentos, coleta de exames, vacinação e farmácia para retirada de medicamentos. $\mathrm{O}$ enfoque nesse contexto são as consultas, os exames e medicamentos. Como apontam Valadão, Lins e Carvalho ${ }^{5}$, um dos principais dificultadores, que culmina em retrocesso para efetivação do novo modelo de atenção, é a transferência do modelo clássico biomédico para a $\mathrm{AB}$. Os profissionais reproduzem em ações cotidianas a centralidade na doença e consulta médica.

\section{MODELO MÉDICO E AUSÊNCIA DE REUNIÕES}

Esse aspecto contextual diz também sobre a estrutura organizacional que delimita as possibilidades de ação dos profissionais. Nesse contexto, não há centralidade na atuação da equipe multiprofissional, mas sim na atuação do médico, com auxílio dos demais profissionais. Há uma divisão do trabalho, tipo de organização pouco adequada à cogestão ${ }^{24}$.

Como não é previsto um trabalho e responsabilização da equipe, 'não há reuniões'. Elas não são previstas ou cobradas como necessárias. O revezamento dos profissionais é também um fator que influencia nesse aspecto de não haver reunião com todos. Esse revezamento se deve ao horário de funcionamento e ao contrato de horas dos 
profissionais de, em sua maioria, 30 horas semanais.

\section{HORÁRIO DE FUNCIONAMENTO}

A UBS não fecha para o almoço ou para reuniões de equipe. Funciona das 7 h00 às 17 h00, e, para que isso aconteça, há o revezamento de duas equipes. Não há, portanto, a possibilidade de reunião com todos, nem no horário de almoço, pois eles se revezam. Sendo assim, o horário de funcionamento não oferece subsídio mínimo para que ocorra uma reunião. Dessa forma, a cultura pouco compartilhada se mantém.

\section{ORGANIZACÃO DO ESPAÇO FÍSICO}

A disposição física se encontra ao redor de um grande pátio em cujo centro há um banco de concreto que atravessa o salão. Ao redor desse pátio, há várias portas, que correspondem às salas de atendimento, de curativo, de medicação, sala do dentista, sala das enfermeiras, sala da gerente, banheiros, recepção e acesso para a cozinha. Não há sala grande onde caibam todos os profissionais em reunião. $\mathrm{Na}$ área externa, o quintal é amplo, mas a farmácia estava sendo construída no momento da pesquisa. Há no pátio, também, diversos murais com alguns informes, bebedouros, ventiladores e uma televisão que nem sempre está ligada.

O movimento na unidade varia muito; em alguns momentos, não há ninguém na sala de espera, já em outros há grande número de pessoas a ponto de não haver espaço para aguardarem sentados. Com maior movimento, o barulho é intenso e o espaço torna-se pouco confortável. Esse fator pode ser uma consequência do número de habitantes da área de abrangência; em 2010 foram estimados, pelo censo do Instituto Brasileiro de Geografia e Estatística (IBGE), 12.331, em comparação à 2.227 habitantes na área de abrangência do NSF 25 .

Valadão, Lins e Carvalho ${ }^{5}$ responsabilizam a precariedade da estrutura física como aspecto que impacta diretamente a realização das atividades dos profissionais. Esse aspecto compromete o processo de trabalho e desmotiva, além de gerar desconforto aos usuários. Os contextos estudados por esses autores também indicam que visitas domiciliares, reuniões de equipe e educação em saúde são deixadas em segundo plano devido à agenda cheia de consultas, algo também observado na UBS tradicional.

\section{Considerações finais}

Conforme analisado, cada contexto possibilita a construção específica de um modelo prático de atenção e gestão que nem sempre funciona de maneira compartilhada, conforme indicam as cartilhas do MS, devido aos aspectos contextuais.

Diferentes estudos ${ }^{\mathbf{8}, \mathbf{1 8 , 2 1 , 2 6}}$ sobre a cogestão indicam desafios para a concretização dessa proposta por meio do maior destaque a aspectos relacionais. Porém, nosso argumento parte da ideia que não basta criar espaço para reunião e decisão coletiva, pois, a depender do modelo de atenção e até mesmo da configuração política do município, pode-se gerar insatisfação dos profissionais que não veem sentido nessa ação, o que invalida a proposta dos espaços para decisão coletiva.

Por outro lado, mudar a organização sem que se promova a transformação nas relações não se mostra efetivo ${ }^{24}$. Como concluem Calderon e Verdi,

Pode-se observar que a cogestão de coletivos organizados para a produção depende de vontade política e de condições objetivas. A proposta é trabalhar sujeitos e instituições. Um movimento interferindo e modificando o outro 18(869).

Nesse sentido, reforçamos o questionamento referido na Introdução, que, embora aspectos relacionais, tecnologias leves, sejam importantes e tenham potencial para promover mudanças, desconsiderar aspectos contextuais 
pode levar a uma isenção do Estado em relação às condições mínimas para a promoção de mudanças.

Compreendemos que o contexto, com seus respectivos modelos de gestão e atenção, delimita possibilidades em relação aos processos de trabalho. Algumas mudanças cabem em cada contexto, outras não; tornam-se incoerentes, como é o caso dos agentes comunitários de saúde alocados por um período na UBS tradicional. A partir do modo como a Unidade funciona, não havia sentido na presença dos agentes, uma vez que o modelo de atenção estava organizado em torno das consultas médicas, e em que o sentido para 'prevenção' se configurou como agendamento antecipado de consultas. Além de perder o sentido, pode levar a uma avaliação negativa desse recurso, que, em outro contexto, como é o caso do NSF, é considerado central para o compartilhamento da gestão e do cuidado em saúde.

Esperamos com esta discussão oferecer subsídios que auxiliem profissionais e gestores a reconhecer a complexidade envolvida na construção da cogestão, tal como a própria política preconiza. Há nela diversos norteadores, que transcendem os aspectos subjetivos, embora esses ganhem, muitas vezes, destaque na literatura. Assim, esperamos que os resultados justifiquem o desenvolvimento de projetos que estejam atentos não somente às relações, mas também aos aspectos concretos do contexto local, social e histórico, alguns nomeados e descritos em nossos resultados.

Definimos como limite deste estudo a não inclusão dos usuários. As análises realizadas partem de conversas com profissionais de saúde. Considerando a proposta da cogestão que conta com o envolvimento dos usuários nesses espaços coletivos de conversa, indicamos a necessidade de novos estudos que contemplem a voz desses atores como central para uma compreensão mais complexa da temática.

\section{Agradecimentos}

Agradecimento à Fundação de Amparo à Pesquisa do Estado de São Paulo (Fapesp), Processo no 2015/04519-6.

\section{Colaboradoras}

Doricci GC (0000-0003-2323-2368)* contribuiu substancialmente para a concepção, planejamento, análise e interpretação dos dados. Guanaes-Lorenzi C (0000-0001-6263-9078)* contribuiu substancialmente para a concepção, planejamento, análise e interpretação dos dados, bem como para a revisão e aprovação da versão final do manuscrito. 


\section{Referências}

1. Doricci GC. Humanização e Cogestão na Atenção Básica: As relações de trabalho no cotidiano. Projeto de Doutorado. Programa de Pós-Graduação em Psicologia Faculdade de Filosofia Ciências e Letras de Ribeirão Preto; 2015. [Material não publicado].

2. Minayo MCS. Prefácio. In: Deslandes SF, organizadora. Humanização dos Cuidados em Saúde: conceitos, dilemas e práticas. Coleção Criança Mulher e Saúde. Rio de Janeiro: Fiocruz; 2006, p. 23-30.

3. Deslandes SF. Humanização: Revisitando o conceito a partir das contribuições da sociedade médica. In: Deslandes SF, organizadora. Humanização dos Cuidados em Saúde: conceitos, dilemas e práticas. Rio de Janeiro: Fiocruz; 2006, p. 33-47. (Coleção Criança Mulher e Saúde).

4. Deslandes SF, Mitre RMA. Processo comunicativo e humanização em saúde. Interface - Comunic., Saúde, Educ. 2009; 13(supl1):641-9.

5. Valadão PAS, Lins L, Carvalho FM. Melhor no passado: a verdadeira saúde da família. Saúde Soc. 2019; 28(1):193-206.

6. Nora CRD, Junges JR. Política de humanização na atenção básica: revisão Sistemática. Rev Saúde Pública. 2013; 47(6):1186-200.

7. Souza DO, Maurício JC. A antinomia da proposta de humanização do cuidado em saúde. Saúde Soc. 2018; 27(2):495-505.

8. Doricci GC, Guanaes-Lorenzi C. Revisão integrativa sobre cogestão no contexto da Política Nacional de Humanização. Ciênc. Saúde Colet. [internet] 2019 [acesso em $2020 \mathrm{mar} 31$ ]. Disponível em: http://www.cienciaesaudecoletiva.com.br/artigos/revisao-integrativa-sobre-cogestao-no-contexto-da-politica-nacional-de-humanizacao/17429?id=17429.

9. Brasil. Ministério da Saúde. Política Nacional de Humanização da Atenção e Gestão do SUS. Gestão Par- ticipativa e Cogestão. Série B. Textos Básicos de Saúde, Brasília, DF: Ministério da Saúde; 2012.

10. Campos GWS. Um método para análise e co-gestão de Coletivos. 3. ed. São Paulo, SP: Hucitec; 2007.

11. Pereira AB, Ferreira Neto JL. Processo de implantação da Política Nacional de Humanização em Hospital Geral Público. TES. 2015; 13(1):67-88.

12. Guanaes C. A Construção da mudança em Terapia de Grupo: um enfoque construcionista social. São Paulo: Vetor; 2006.

13. McNamee S. Construindo conhecimento / construindo investigação: coordenando mundos de pesquisa. In: Guanaes-Lorenzi C, Moscheta MS, Corradi-Webster CM, et al., organizadores. Construcionismo Social: discurso, prática e produção do conhecimento. Rio de Janeiro: Instituto Noos; 2014. p. 105-132.

14. Minayo MCS. Análise qualitativa: teoria, passos e fidedignidade. Ciênc. Saúde Colet. 2012; 17(3):621-626.

15. Conselho Nacional de Saúde. Resolução $n^{0} 466$, de 12 de dezembro de 2012. [internet]. 2012. [acesso em 2015 jan 10]. Disponível em: http://conselho.saude. gov.br/resolucoes/2012/Reso466.pdf.

16. Ribeirão Preto. Secretaria Municipal de Saúde. [acesso em 2017 dez 20]. Disponível em: http://www.ribeiraopreto. sp.gov.br/ssaude/il6saude.php.

17. Caccia-Bava, MCGG. Relatório Técnico 2005. Ribeirão Preto: Centro de Saúde Escola da Faculdade de Medicina de Ribeirão Preto; 2005. [Material não publicado].

18. Calderon DBL, Verdi MIM. Cogestão e processo de intervenção de apoiadores da Política Nacional de Humanização (PNH). Interface (Botucatu). 2014; 18(supl1):859-70.

19. Mailhiot GB. Dinâmica e gênese dos grupos: atualidades e descobertas de Kurt Lewin. Rio de Janeiro: Vozes; 2013. 
20. Brasil. Portaria $\mathrm{n}^{\circ} 2.436$, de 21 de setembro de 2017. Aprova a Política Nacional de Atenção Básica, estabelecendo a revisão de diretrizes para a organização da Atenção Básica, no âmbito do Sistema Único de Saúde (SUS); 2017. [acesso em 2020 jan 6]. Disponível em: https://bvsms.saude.gov.br/bvs/saudelegis/ gm/2017/prt2436_22_09_2017.html.

21. Verdi M, Caetano TL, Navarro, LM, et al. A cogestão e a inclusão na formação de apoiadores da Política Nacional de Humanização nos territórios do Rio Grande do Sul, Santa Catarina e São Paulo. Sau. \& Transf. Soc. 2014; 5(2):50-58.

22. Guanaes-Lorenzi C, Pinheiro RL. A (des)valorização do agente comunitário de saúde na Estratégia Saúde da Família. Ciênc. Saúde Colet. [internet]. 2016; 21(8):2537-2546 [acesso em 2020 jul 30]. Disponível em: http://www.scielo.br/scielo.php?script=sci arttext\&pid=S1413-81232016000802537\&lng=en. https://doi.org/10.1590/1413-81232015218.19572015.
23. Pastana ICS, Pereira EC, Lima JCS, et al. Práticas humanizadoras na Atenção Básica: uma revisão sistemática qualitativa. Bis, Bol. Inst. Saúde (Impr.). 2019; 20(2):54-62.

24. Guizardi FL, Cavalcanti FOL. O conceito de cogestão em saúde: reflexões sobre a produção de democracia institucional. Physis. 2010; 20(4):1245-1265.

25. Ribeirão Preto. Prefeitura Municipal. [acesso em 2018 jan 12]. Disponível em: https://www.ribeiraopreto. sp.gov.br/saude/rede/oeste/i16usf-n-6.php.

26. Fernandes JA, Figueiredo, MD. Apoio institucional e cogestão: uma reflexão sobre o trabalho dos apoiadores do SUS Campinas. Physis. 2015; 25(1):287-306.

Recebido em 02/04/2020

Aprovado em 06/08/2020

Conflito de interesses: inexistente

Suporte financeiro: Fundação de Amparo à Pesquisa do Estado de

São Paulo (Fapesp), Processo no 2015/04519-6 